\title{
Co-Relation of Left Ventricular Diastolic Dysfunction with Apache II Score in Sepsis Patients
}

\section{IJCRR}

Section: Healthcare Sci. Journal Impact Factor: 6.1 (2018) ICV: $90.90(2018)$

Scopus'

\section{Anjalee Chiwhane ${ }^{1}$, Yogesh Khithani ${ }^{2}$, Anuj Varma ${ }^{3}$, Saurabh Hadke}

\begin{abstract}
'Professor Department of Medicine Jawaharlal Nehru Medical College, Datta Meghe Institute of Medical Sciences, Sawangi Wardha Maharashtra-442001; ${ }^{2}$ Resident Department of Medicine Jawaharlal Nehru Medical College, Datta Meghe institute of Medical Sciences, Sawangi Wardha Maharashtra-442001; 3Assistant Professor Department of Medicine Jawaharlal Nehru Medical College, Datta Meghe Institute of Medical Sciences, Sawangi Wardha Maharashtra-442001; ${ }^{4}$ Assistant Professor Department of General Medicine Datta Meghe Medical College, Shalinitai Meghe Hospital and Research Centre Nagpur-441110.
\end{abstract}

\section{ABSTRACT}

Background: Sepsis is a leading cause of mortality and is a major cause of morbidity by causing end-organ damage as well as cognitive and physical disability in survivors. Sepsis can be defined as the presence (probable or documented) of infection together with systemic manifestation of infection. Patients with sepsis generally have multiple predisposing factors and sources of infection. Cardiac dysfunction adds up in increasing the mortality rate in patients with sepsis. Diastolic dysfunction can predict long term mortality and morbidity in sepsis and is recognized to be a major cause of heart failure with normal ejection fraction (LVEF>55\%).

Material and Methods: The study was done on subjects admitted in ICU under the department of Medicine. All patients above 18 years, those who gave their consent for the study or their relatives, also fulfilled the criteria for sepsis as mentioned in guidelines for sepsis. Though the calculated sample size with $50 \%$ proportion of sepsis in two years was 127 , this study included 140 patients. Worst APACHE II scores were calculated during the period of admission within the first 24 hours. All the pathological and biochemical parameters were measured by standard laboratory techniques. Blood pressure was measured using a mercury sphygmomanometer, using a Riva-Roci cuff in the right hand in the supine position. Worst APACHE II score was calculated in the first 24 hours for the sepsis patients admitted in the Medicine intensive care unit and was interpreted.

Results: In the present study on 140 patients, the mean age of patients was $50.15 \pm 16.37$ years. This study population was male dominant where $94(67.14 \%)$ were males and 46 (32.86\%) were females. Out of the total study population, 104 (74.3\%) were survivors while 36 (25.7\%) were non-survivors. Worse APACHE II score from 20 to 34 had a greater number of patients with left ventricular diastolic dysfunction. When the APACHE II score was correlated with the presence of LVDD in both survivors and non-survivors, it was observed that in the non-survivors as the APACHE II score worsens from 20 to 34 , there was significant mortality as compared with the survivors.

Conclusion: LVDD was present in patients above the age of 40 years. As the APACHE II score worsens from 20 to 34 , a greater number of patients showed LVDD. When APACHE II score was correlated with presence of LVDD in both survivors and nonsurvivors, it was observed that in the non-survivors as the APACHE II score worsens from 20 to 34 and there was a significant mortality as compared with the survivors.

Key Words: Sepsis, LVDD, APACHE II

\section{INTRODUCTION}

Sepsis is a leading cause of mortality and is a major cause of morbidity by causing end-organ damage as well as cognitive and physical disability in survivors ${ }^{1,2}$.

Sepsis can be defined as the presence (probable or documented) of infection together with systemic manifestation of infection $^{3}$. Despite significant advancements in the understanding of the pathophysiology of sepsis, advancements in hemodynamic monitoring tools, and resuscitation measures, sepsis remains one of the major causes of morbidity and mortality in critically ill patients ${ }^{4}$. In United States of America, annual incidence of severe sepsis and septic shock is up to 300 cases per 100,000 people. The hospital stay of a patient with sepsis is nearly twice and the mortality rate is 8 times more than that of other patients ${ }^{1,5}$.

\section{Corresponding Author:}

Dr Yogesh Khithani, Senior Resident Department of Medicine, Jawaharlal Nehru Medical College, Datta Meghe Institute of Medical Sciences, Sawangi Wardha Maharashtra-442001.

ISSN: 2231-2196 (Print)

Received: 11.05 .2020
ISSN: 0975-5241 (Online)

Revised: 03.06 .2020
Accepted: 11.06 .2020 
Patients with sepsis generally have multiple predisposing factors and sources of infection. Cardiac dysfunction adds up in increasing the mortality rate in patients with sepsis ${ }^{6}$. When compared to patients who don't have left ventricular diastolic dysfunction, patients who develop left ventricular diastolic dysfunction during sepsis have worse prognosis ${ }^{7},{ }^{8}$.

Diastolic dysfunction can predict long term mortality and morbidity in sepsis and is recognized to be a major cause of heart failure with normal ejection fraction(LVEF $>55 \%$ ). Only a few studies and limited data are available on cardiac dysfunction in sepsis and septic shock and also on the prognostic importance of diastolic dysfunction in sepsis and septic shock ${ }^{9},{ }^{10},{ }^{11}$.

There is sufficient data of LVDD (left ventricular diastolic dysfunction) in sepsis and its impact on outcome from developing countries. However, there is insufficient evidence from middle and low income countries.

Hence the objective of this study was to see LVDD in sepsis patients from a tertiary rural hospital and to co-relate left ventricular diastolic dysfunction with APACHE II score.

\section{MATERIAL AND METHODS}

\section{Study setting}

This present study was conducted in medicine ICU of Department of Medicine, Acharya Vinoba Bhave Rural Hospital (AVBRH) JNMC Sawangi, a tertiary care teaching hospital situated in the rural area of Wardha District.

\section{Duration and type of study}

The study was a cross-sectional study. The study was done on subjects admitted in ICU under the department of Medicine from September 2016 to August 2018.

\section{Ethics Committee Permission}

This study was initiated after obtaining clearance from the institutional ethics committee on Date: 30/9/2016 with reference number: DMIMS(DU)/IEC/2016-17/4079.

\section{Inclusion Criteria}

CASE: All patients above 18 years, those who gave their consent for the study or their relatives, also fulfilled the criteria for sepsis as mentioned in guidelines for sepsis ${ }^{12}$.

Exclusion Criteria: any severe debilitating illness with or without

- Chronic hypertension

- Myocardial disease

- Pericardial disease

- Valvular heart disease
- Coronary artery Disease

- Major cardiac dysrhythmias

- 2D echo showing Regional Wall Motion Abnormality or LVEF (left ventricular ejection fraction ) less than $55 \%$.( normal EF more than 55\%)

\section{Sample size}

All consecutive patients admitted in ICU under Department of Medicine from September 2016 to August 2018 were enrolled in the study.

Though the calculated sample size with $50 \%$ proportion of sepsis in two years was 127 , this study included 140 patients. Total patients admitted to AVBRH of sepsis from October 2016 to August 2018 in two years due to sepsis $=\mathrm{N}=127$.

\section{Methodology}

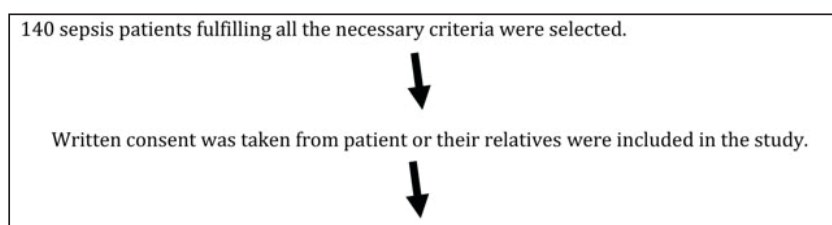

All admitted patients in medicine intensive care unit were clinically assessed for sepsis by clinical and biochemical investigations.

\section{$\downarrow$}

Past medical records or documents suggesting any past history of chronic hypertension, myocardial disease, pericardial disease, valvular heart disease, coronary artery disease, major cardiac dysrhythmias, $2 \mathrm{~d}$ echo showing regional motion abnormality or LVEF less than $55 \%$ were excluded.

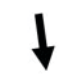

Appropriate Cultures (from source of infection), along with samples for CBC, LFT, KFT, $\mathrm{ABG}, \mathrm{C}$-reactive protein were sent.

\section{$\downarrow$}

Admitted patients of sepsis underwent bedside 2D Echo.[model Wipro GE Vivide SR460051WXE(15)] and E Wave, A wave, septal e' were measured and E/A, E/septal e' were calculated.

$\checkmark$

Worst APACHE II scores were calculated during the period of admission within first 24 hours.

All the pathological and biochemical parameters were measured by standard laboratory techniques.

Blood pressure was measured using a mercury sphygmomanometer, using a Riva-Rocci cuff in the right hand in the supine position.

\section{APACHE II SCORE}

APACHE II ("Acute Physiology And Chronic Health Evaluation II") is a severity-of-disease classification system. Worst APACHE II score was calculated in the first 24 hours for the sepsis patients admitted in Medicine intensive care unit and was interpreted according to table: 1 
Table 1: APACHE II SCORE with Approximate mortality ${ }^{13}$

\begin{tabular}{ll}
\hline o to 4 points & $4 \%$ non - operated, $1 \%$ post - operated \\
$\mathbf{5}$ to 9 points & $8 \%$ non - operated, $3 \%$ post - operated \\
10 to 14 points & $15 \%$ non - operated, $7 \%$ post - operated \\
$\mathbf{1 5}$ to 19 points & $24 \%$ non - operated, $12 \%$ post - operated \\
20 to 24 points & $40 \%$ non - operated, 30\% post - operated \\
$\mathbf{2 5}$ to 29 points & $55 \%$ non - operated, 35\% post - operated \\
30 to 34 points & Approximate $73 \%$ both \\
35 to 10o points & $85 \%$ non - operated, $88 \%$ post - operated \\
\hline
\end{tabular}

\section{Statistical analysis}

All Statistical analysis was done by using SPSS (statistical package of social science) 22.0 version and Graph Pad Prism 6.0 version.

The data were presented as mean for continuous variables or absolute number (\%) for categorical variables unless otherwise specified. A 'p' value $<0.05$ was considered statistically significant.

\section{RESULTS}

In the present study on 140 patients, the mean age of sepsis patients in our study was $50.15 \pm 16.37$ years. This study population was male dominant where 94 (67.14\%) were males and $46(32.86 \%)$ were females. Out of the total study population, $104(74.3 \%)$ were survivors while $36(25.7 \%)$ were non-survivors. CKD was present in $35(25 \%)$ patients, 49 (35\%) were DM, $9(6.43 \%)$ were cirrhosis of the liver, and $23(16.42 \%)$ were others like (COPD, HIV, HBsAg, MALIGNANCY).

Table 2: Baseline characteristics of study subjects (total number of sepsis patients $\mathrm{n}=\mathbf{1 4 0}$ )

$\begin{aligned} & \text { Baseline } \\ & \text { characteristics }\end{aligned}$
$\begin{aligned} & \text { No. of Percentage Mean } \pm \text { SD } \\ & \text { patients }\end{aligned}$

Age(years) $\quad 50.15 \pm 16.37$

Male
Female
Temperature
('Fahrenheit)
SBP (mmhg)
DBP(mmhg)
MAP(mmhg)
Pulse Rate(bpm)
RR(cpm)
APACHE Score

\section{Gender}

$94 \quad 67.14 \%$

$46 \quad 32.86 \%$

\section{Clinical Parameters}

Temperature

$\left({ }^{\circ}\right.$ Fahrenheit $)$

SBP (mmhg)

$\mathrm{DBP}(\mathrm{mmhg})$

MAP(mmhg)

$\mathrm{RR}(\mathrm{cpm})$

APACHE Score

$61.45 \pm 24.40$

$74.45 \pm 23.62$

$113.74 \pm 10.25$

$25.85 \pm 4.34$

$25 \cdot 57 \pm 4.80$
Table 2: (Continued)

\begin{tabular}{lcc}
$\begin{array}{l}\text { Baseline } \\
\text { characteristics }\end{array}$ & $\begin{array}{c}\text { No. of } \\
\text { patients }\end{array}$ & Percentage \\
Comorbidities & Mean \pm SD \\
CKD & 35 & $25 \%$ \\
DM & 49 & $35 \%$ \\
Cirrhosis & 9 & $6.43 \%$ \\
Others & 23 & $16.42 \%$ \\
\hline
\end{tabular}

Table 3: Left ventricular diastolic dysfunction in sepsis between gender (total number of sepsis patients $\mathrm{n}=\mathbf{1 4 0}$ )

\begin{tabular}{lccc}
$\begin{array}{l}\text { Left ventricular } \\
\text { diastolic } \\
\text { dysfunction }\end{array}$ & Male (n=94) & $\begin{array}{c}\text { Female } \\
(\mathbf{n = 4 6})\end{array}$ & $\begin{array}{c}\text { Total (total } \\
\text { number } \\
\text { of sepsis } \\
\text { patients n }\end{array}$ \\
Present & $58(69.88 \%)$ & $25(30.12 \%)$ & $83(59.29 \%)$ \\
Absent & $36(63.13 \%)$ & $21(36.87 \%)$ & $57(40.71 \%)$ \\
Total & $94(67.14 \%)$ & $46(32.86 \%)$ & $140(100 \%)$ \\
N2-value & \multicolumn{4}{c}{$0.69, \mathrm{p}$-value $=0.40, \mathrm{NS}, \mathrm{p}>0.05$} \\
\hline
\end{tabular}

It was observed that out of 83 patients having left ventricular diastolic dysfunction, 58(69.88\%) were males and $25(30.12 \%)$ were females. It was seen that when left ventricular dysfunction was compared between the gender (males and females), it was seen more in males.

Table 4: Correlation of APACHE-II score with left ventricular diastolic dysfunction (total number of sepsis patients $n=140$ )

$\begin{array}{lrr}\begin{array}{l}\text { APACHE- } \\ \text { II Scoring } \\ \text { points }\end{array} & \text { No of patients } & \begin{array}{r}\text { Left ventricular diastolic } \\ \text { dysfunction }\end{array} \\ \text { Present Absent }\end{array}$

\begin{tabular}{lccc}
\hline o to 4 & o & & \\
5 to 9 & o & & \\
10 to 14 & 1 & $1(100 \%)$ & o(o\%) \\
15 to 19 & 13 & $4(30.77 \%)$ & $9(69.23 \%)$ \\
20 to 24 & 44 & $18(40.91 \%)$ & $26(59.09 \%)$ \\
25 to 29 & 52 & $36(69.23 \%)$ & $16(30.77 \%)$ \\
30 to 34 & 26 & $21(80.77 \%)$ & $5(19.23 \%)$ \\
35 to 100 & 4 & $3(75 \%)$ & $1(25 \%)$ \\
Total & 140 & $83(59.29 \%)$ & $57(40.71 \%)$ \\
N2-value & & $18.73, \mathrm{P}=0.0022, \mathrm{~S}, \mathrm{p}<0.05$ \\
\hline
\end{tabular}

It was observed that, 13 patients had APACHE II score between 15 to 19, out of which 4(30.77\%) patients had LVDD. 44 patients had APACHE2 score between 20 to 24,out of 
which 18(40.91\%) patients had LVDD. 52 patients had APACHE II score between 25 to 29 , out of which $36(69.23 \%)$ patients had LVDD. 26 patients had APACHE II score between 30 to 34 , out of which $21(80.77 \%)$ patients had LVDD. 4 patients had APACHE II score between 35 to 100 , out of which $3(75 \%)$ patients had LVDD. In this table, it was observed that higher APACHE II score between 20 to 34 had a greater number of patients with left ventricular diastolic dysfunction.

It was observed that 13 patients had APACHE II scores between 15 to 19 out of which 4 (3.85\%) patients who survived had LVDD. 44 patients had APACHE II score between 20 to 24 , out of which $13(12.50 \%)$ patients who survived had LVDD and out of non-survived patients, 5 (13.89\%) patients had LVDD. 52 patients had APACHE II score between 25 to 29 , out of which $23(22.12 \%)$ patients who survived had
LVDD and out of non-survived patients, 13 (36.11\%) patients had LVDD. 26 patients had APACHE II score between 30 to 34 , out of which $11(10.58 \%)$ patients who survived had LVDD and out of non-survived patients, 10 (27.78\%) patients had LVDD. 4 patients had APACHE II score between 35 to 100 , out of which $3(8.33 \%)$ patients who died had LVDD.

When the APACHE II score was correlated with the presence of LVDD in both survivors and non-survivors, it was observed that in the non-survivors as the APACHE II score worsens from 20 to 34 , there was significant mortality as compared with the survivors.

In our study, it was observed that the mean age among survivors was $48.41 \pm 15.97$ years, while in non-survivors were $55.16 \pm 16.70$ years.

Table 5: Table showing correlation of outcome and APACHE-II score with-in hospital mortality and left ventricular diastolic dysfunction (total number of sepsis patients $n=140$ )

\begin{tabular}{|c|c|c|c|c|c|}
\hline \multirow{3}{*}{$\begin{array}{l}\text { APACHE-II Scoring } \\
\text { points }\end{array}$} & \multirow{3}{*}{$\begin{array}{c}\text { No of } \\
\text { patients }\end{array}$} & \multicolumn{4}{|c|}{ Actual Outcome } \\
\hline & & \multicolumn{2}{|c|}{ Survivor $(\mathrm{n}=104)$} & \multicolumn{2}{|c|}{ Non Survivor $(n=36)$} \\
\hline & & $\begin{array}{c}\text { Left ventricular } \\
\text { diastolic dysfunction } \\
\text { present }\end{array}$ & $\begin{array}{c}\text { Left ventricular } \\
\text { diastolic dysfunction } \\
\text { absent }\end{array}$ & $\begin{array}{l}\text { Left ventricular } \\
\text { diastolic dysfunc- } \\
\text { tion present }\end{array}$ & $\begin{array}{c}\text { Left ventricular } \\
\text { diastolic dysfunction } \\
\text { absent }\end{array}$ \\
\hline 10 to 14 & 1 & $1(0.96 \%)$ & $\mathrm{o}(\mathrm{o} \%)$ & $\mathrm{o}(\mathrm{o} \%)$ & $\mathrm{o}(\mathrm{o} \%)$ \\
\hline 15 to 19 & 13 & $4(3.85 \%)$ & $9(8.65 \%)$ & $\mathrm{o}(\mathrm{o} \%)$ & $\mathrm{o}(\mathrm{o} \%)$ \\
\hline 20 to 24 & 44 & $13(12.50 \%)$ & $25(24.04 \%)$ & $5(13.89 \%)$ & $1(2.78 \%)$ \\
\hline 25 to 29 & 52 & $23(22.12 \%)$ & $14(13.46 \%)$ & $13(36.11 \%)$ & $2(5 \cdot 56 \%)$ \\
\hline 30 to 34 & 26 & $11(10.58 \%)$ & $3(2.88 \%)$ & $10(27.78 \%)$ & $2(5 \cdot 56 \%)$ \\
\hline 35 to 100 & 4 & $\mathrm{o}(\mathrm{o} \%)$ & $1(0.96 \%)$ & $3(8.33 \%)$ & $\mathrm{o}(\mathrm{o} \%)$ \\
\hline Total & 140 & $52(50 \%)$ & $52(50 \%)$ & $31(86.11 \%)$ & $5(13.89 \%)$ \\
\hline ふ2-value & & \multicolumn{2}{|c|}{$14.47, \mathrm{p}=0.012, \mathrm{~S}, \mathrm{p}<0.05$} & \multicolumn{2}{|c|}{$29.09, \mathrm{p}=0.0001, \mathrm{~S}, \mathrm{p}<0.05$} \\
\hline
\end{tabular}

( $\mathrm{p}$ value to be significant is $<0.05$ )

\section{DISCUSSION}

Sepsis is characterized by circulatory abnormalities resulting in intravascular volume depletion and vasodilatation and causes oxygen supply-demand imbalance in the tissues, the cardiac performance is likely to be reduced due to major changes in the cardio microcirculation due to endothelial disruption and maldistribution of blood flow as a result of sepsis leading to cardiac dysfunction. When compared to patients without left ventricular diastolic dysfunction, patients who develop left ventricular diastolic dysfunction during sepsis have a worse prognosis ${ }^{8,9}$. Diastolic and systolic dysfunctions have been focused separately in most of the researches on cardiovascular dysfunctions in septic patients ${ }^{14,15}$.

Sepsis was seen across all age groups in this present study population of 140 patients. The mean age of the patient population in this present study having sepsis was $50 \pm 16$ years.

While investigating gender distribution among 140 sepsis patients, $94(67 \%)$ were males and $46(33 \%)$ were females in this present study. Gustavo Rolando et al. ${ }^{16}$ conducted a study, in which the mean age was $74 \pm 13$ years. It had $55 \%$ males and $45 \%$ females. In other study conducted by T. Furian et al. ${ }^{17}$, mean age was $51 \pm 18$ years having $35 \%$ males and $65 \%$ females in the study. Clancy DJ et al. ${ }^{18}$ conducted a study in which mean age was $63.1 \pm 12.4$ years and there were $56 \%$ males and $44 \%$ females.

In this present study, LVDD was seen to be statistically significant in patients above the age of 40 years in both males and females. However, its presence in both males and females was not comparable. Juan N. Pulido et al. ${ }^{19}$ conducted 
a study showing the statistical difference between survivors and non-survivors including APACHE II score, SOFA score, and $\mathrm{PaO}_{2} / \mathrm{FiO}_{2}$ ratio. In another study by $\mathrm{Y}$. Mahjoub et al. ${ }^{20}$, HR, SBP, DBP, MAP was found to be insignificant in survivors and non-survivors. Likewise, T. Furian et al. ${ }^{21}$ in their study observed that the APACHE II score, SBP, HR were not significant. Landersberg et al. ${ }^{15}$ study observed that the APACHE II and SOFA scores were significant between survivors and non-survivors.

Percentage of LVDD in sepsis patients in this present study was $59.29 \%$ and in other studies like Gustavo Rolando et al. ${ }^{17}$ it was $84 \%$ and in Juan N. Pulido et al. ${ }^{20}$ it was $84 \%$. Juan N. Pulido et al. ${ }^{20}$ conducted a study in which it was observed that patients having Left ventricular diastolic dysfunction were much older (72 years).

In a study by Munt B et $\mathrm{al}^{22}$, it was observed that the APACHE II score and deceleration time were important predictors of mortality. When this was compared with the present study, it was seen that APACHE II score correlated with the presence of left ventricular diastolic dysfunction in both survivors and non-survivors and also had a significant effect on the mortality.

\section{CONCLUSION}

In the present study when LVDD was compared across age distribution in males and females, it was observed that LVDD was present in patients above the age of 40 years which was statistically significant. As the APACHE II score worsened from 20 to 34, a greater number of patients LVDD was detected. When the APACHE II score was correlated with the presence of LVDD in both survivors and non-survivors, it was observed that in the non-survivors as the APACHE II score worsened from 20 to 34, there was significant mortality as compared with the survivors in this present study.

Acknowledgement: Authors acknowledge the immense help received from the scholars whose articles are cited and included in references of this manuscript. The authors are also grateful to authors / editors / publishers of all those articles, journals and books from where the literature for this article has been reviewed and discussed.

\section{Conflict of interest: none}

Financial support: none

\section{REFERENCES}

1. Hall MJ, DeFrances CJ. Inpatient Care for Septicemia or Sepsis: A Challenge for Patients and Hospitals. 2011 June;(62):8

2. Angus DC, Linde-Zwirble WT, Lidicker J, Clermont G, Carcillo J, Pinsky MR. Epidemiology of severe sepsis in the United States: analysis of incidence, outcome, and associated costs of care. Crit Care Med. 2001 Jul;29(7):1303-10.
3. Bacon BR. Harrison's Principles of Internal Medicine. 19e. Available from: https://accessmedicine.mhmedical.com/book. aspx?bookID=1130

4. Kaukonen KM, Bailey M, Suzuki S, Pilcher D, Bellomo R. Mortality related to severe sepsis and septic shock among critically ill patients in Australia and New Zealand, 2000-2012. JAMA. 2014 Apr 2; 311(13):1308-16.

5. Hall MJ, DeFrances CJ, Williams SN, Golosinskiy A, Schwartzman A. National Hospital Discharge Survey: 2007 summary. Natl Health Stat Report. 2010 Oct 26;(29):1-20, 24.

6. Kollef MH, Ladenson JH, Eisenberg PR. Clinically recognized cardiac dysfunction: an independent determinant of mortality among critically ill patients. Is there a role for serial measurement of cardiac troponin I? Chest. 1997 May;111(5):1340-7

7. Maeder M, Fehr T, Rickli H, Ammann P. Sepsis-associated myocardial dysfunction: diagnostic and prognostic impact of cardiac troponins and natriuretic peptides. Chest. 2006 May $1 ; 129(5): 1349-66$.

8. Poelaert J, Declerck C, Vogelaers D, Colardyn F, Visser CA. Left ventricular systolic and diastolic function in septic shock. Intensive Care Med. 1997 May;23(5):553-60.

9. Bouhemad B, Nicolas-Robin A, Arbelot C, Arthaud M, Féger F, Rouby JJ. Isolated and reversible impairment of ventricular relaxation in patients with septic shock. Critical care medicine. 2008 Mar 1;36(3):766-74

10. Landesberg G, Gilon D, Meroz Y, Georgieva M, Levin PD, Goodman S, et al. Diastolic dysfunction and mortality in severe sepsis and septic shock. Eur Heart J. 2012 Apr;33(7):895-903

11. Ikonomidis I, Nikolaou M, Dimopoulou I, Paraskevaidis I, Lekakis J, Mavrou I, Tzanela M, Kopterides P, Tsangaris I, Armaganidis A, Kremastinos DT. Association of left ventricular diastolic dysfunction with elevated NT-pro-BNP in general intensive care unit patients with preserved ejection fraction: a complementary role of tissue Doppler imaging parameters and NT-pro-BNP levels for adverse outcome. Shock. 2010 Feb 1;33(2):141-8

12. Dellinger RP, Levy MM, Rhodes A, Annane D, Gerlach H, Opal SM, et al. Surviving Sepsis Campaign: international guidelines for management of severe sepsis and septic shock, 2012. Intensive Care Med. 2013 Feb;39(2):165-228

13. Knaus WA, Draper EA, Wagner DP, Zimmerman JE. APACHE II: a severity of disease classification system. Crit Care Med. 1985 Oct;13(10):818-29.

14. Landesberg G, Gilon D, Meroz Y, Georgieva M, Levin PD, Goodman S, et al. Diastolic dysfunction and mortality in severe sepsis and septic shock. Eur Heart J. 2012 Apr;33(7):895-903.

15. Parker MM, McCarthy KE, Ognibene FP, Parrillo JE. Right ventricular dysfunction and dilatation, similar to left ventricular changes, characterize the cardiac depression of septic shock in humans. Chest. 1990 Jan;97(1):126-31.

16. Rolando G, Espinoza ED, Avid E, Welsh S, Pozo JD, Vazquez AR, Arzani Y, Masevicius FD, Dubin A. Prognostic value of ventricular diastolic dysfunction in patients with severe sepsis and septic shock. Revista Brasileira de terapia intensiva. 2015 Dec;27(4):333-9

17. Furian T, Aguiar C, Prado K, Ribeiro RVP, Becker L, Martinelli $\mathrm{N}$, et al. Ventricular dysfunction and dilation in severe sepsis and septic shock: relation to endothelial function and mortality. J Crit Care. 2012 Jun;27(3):319.e9-15

18. Clancy DJ, Scully T, Slama M, Huang S, McLean AS, Orde SR. Application of updated guidelines on diastolic dysfunction in patients with severe sepsis and septic shock. Ann Intensive Care. 2017 Dec 19;7(1):121.

19. Pulido JN, Afessa B, Masaki M, Yuasa T, Gillespie S, Herasevich V, Brown DR, Oh JK. Clinical spectrum, frequency, and 
significance of myocardial dysfunction in severe sepsis and septic shock. InMayo Clinic Proceedings 2012 Jul 1 (Vol. 87, No. 7, pp. 620-628). Elsevier.

20. Mahjoub Y, Benoit-Fallet H, Airapetian N, Lorne E, Levrard M, Seydi A-A, et al. Improvement of left ventricular relaxation as assessed by tissue Doppler imaging in fluid-responsive critically ill septic patients. Intensive Care Med. 2012 Sep;38(9):1461-70.
21. Furian T, Aguiar C, Prado K, Ribeiro RVP, Becker L, Martinelli $\mathrm{N}$, et al. Ventricular dysfunction and dilation in severe sepsis and septic shock: relation to endothelial function and mortality. J Crit Care. 2012 Jun;27(3):319.e9-15.

22. Munt B, Jue J, Gin K, Fenwick J, Tweeddale M. Diastolic filling in human severe sepsis: an echocardiographic study. Crit Care Med. 1998 Nov;26(11):1829-33. 